DOI 10. 18307/2019. 0511

(C) 2019 by Journal of Lake Sciences

\title{
内蒙古达里诺尔湖水体稳定同位素空间分布特征指示的区域补给 差异
}

李文宝, 杜蕾, 王旭阳, 杨 旭, 史小红

(内蒙古农业大学水资源保护与利用自治区重点实验室, 呼和浩特 010018)

摘 要: 基于内蒙古寒旱区达里诺尔湖 (简称 “达里湖”) 无河流外泄、冬季湖面冰封、水体流动缓慢等典型区域水文气象 特征,对夏、冬季湖泊底层、表层水 (冰)、人湖河水、浅层地下水 (井水、泉水) 等样品中稳定氢、氧同位素 $\left(\delta \mathrm{D} 、 \delta^{18} \mathrm{O}\right)$ 值的 变化进行对比分析, 结果显示湖区不同水体 $\delta \mathrm{D}$ 和 $\delta^{18} \mathrm{O}$ 平均值均存在湖泊水体 (水、冰体) $>$ 大气降水 $>$ 人湖河水 $>$ 浅层地 下水的变化特征. 在达里湖, 夏、冬季底层水 $\delta \mathrm{D} 、 \delta^{18} \mathrm{O}$ 值均比表层水 (含湖冰) 中 $\delta \mathrm{D} 、 \delta^{18} \mathrm{O}$ 值偏负且季节变化幅度较小. 此 外, 冬季不同采样点底层水 $\delta \mathrm{D} 、 \delta^{18} \mathrm{O}$ 平均值的区域差异性比夏季明显, 这反映了湖泊底层水体相对封闭、稳定的储存环 境, 也说明地下水补给过程存在一定程度的区域差异. 而基于不同区域底层水 $\delta \mathrm{D} 、 \delta^{18} \mathrm{O}$ 值及氝盈余指数 $(d)$ 值和水深变 化间相互关系的分析, 发现水深变化可能是影响达里湖底层水 $\delta \mathrm{D} 、 \delta^{18} \mathrm{O}$ 值分布区域差异及补给过程的主要因素之一: 东 北部水体较浅 (水深小于 $8 \mathrm{~m}$ ) 区域采样点水体 $\delta \mathrm{D} 、 \delta^{18} \mathrm{O}$ 平均值多数比达里湖整体平均值偏负且 $d$ 值偏正, 指示浅层地 下水输人及二次蒸发作用的影响; 西南部水体较深 (水深超过 $8 \mathrm{~m}$ ) 区域采样点水体 $\delta \mathrm{D} 、 \delta^{18} \mathrm{O}$ 平均值多数比达里湖整体平 均值偏正且 $d$ 值偏负, 说明水体相对稳定,受二次蒸发作用的影响较弱.

关键词: 氢一氧同位素;空间分布;湖泊水体;补给特征;达里诺尔湖

\section{Regional groundwater recharges based on the characteristics of stable isotope distribution in Dali-nor Lake in Inner Mongolia}

LI Wenbao, DU Lei, WANG Xuyang, YANG Xu \& SHI Xiaohong

(Inner Mongolia Agricultural University IMAR Key Laboratory of Water Resources Protection and Utilization, Hohhot 010018 , P.R.China)

Abstract: The Dali-nor Lake is a typical closed lake in Inner Mongolia, the cold and arid area in Northern China, which has no surface water discharges by rivers. In particular, the surface water of the lake would be frozen with very slowly water flows in winter. The lake can be regarded as nearly sealed and only influenced by groundwater recharges in winter. According to regional hydrologic and meteorological characteristics, the winter is an ideal stage to study the recharge process of bottom water in Dali-nor Lake. Therefore, we collected samples of lake water, lake ice, river water, shallow groundwater and rainfall, and analyzed the values of hydrogen and oxygen isotopes $\left(\delta \mathrm{D}\right.$ and $\left.\delta^{18} \mathrm{O}\right)$ of these water samples from the lake. The results show that the average values of $\delta \mathrm{D}$ and $\delta^{18} \mathrm{O}$ are the heaviest in samples from the lake water and ice, and the average values of $\delta \mathrm{D}$ and $\delta^{18} \mathrm{O}$ in shallow groundwater are the lightest, relatively. Meanwhile, the average values of $\delta \mathrm{D}$ and $\delta^{18} \mathrm{O}$ are about $-31.51 \%$ and $-2.05 \%$ in bottom water and about $-32.77 \%$ and $-2.51 \%$ in surface water in winter, respectively. But the average values of $\delta \mathrm{D}$ and $\delta^{18} \mathrm{O}$ in bottom water are lighter than those in surface water and ice, with values of about $-29.12 \%$ and $-1.84 \%$. In summer, the average values of $\delta \mathrm{D}$ and $\delta^{18} \mathrm{O}$ in bottom water are also lighter than those in surface water, with values of about $-32.95 \%$ and $2.13 \%$ in bottom water and $-32.61 \%$ and $-1.99 \%$ in surface water, respectively. It's likely that the different $\delta \mathrm{D}$ and $\delta^{18} \mathrm{O}$ values between bottom and surface water had been influenced by seasonal changes and frozen processes in Dali-nor Lake. As a whole, the values of $\delta \mathrm{D}$ and $\delta{ }^{18} \mathrm{O}$ in bottom water are lighter than those in surface water, and the regional differences of $\delta \mathrm{D}$ and $\delta^{18} \mathrm{O}$ values are also more distinct than those in summer bottom water. On the other hand, the relationships between water depth and lake water stable isotopes had shown

* 国家自然科学基金项目 (51669021,51469025) 和内蒙古自治区自然科学基金项目 (2016MS0552) 联合资助. 201811-20 收稿;2019-03-21 收修改稿. 李文宝(1980 ), 男, 博士, 副教授;E-mail: tianshiTD@ 126.com. 
that changes in the water depth were one primary factor that influenced the value changes of $\delta \mathrm{D}$ and $\delta{ }^{18} \mathrm{O}$ in bottom water in Dalinor Lake. As results, the shallow water area, where water depth is lower than $8 \mathrm{~m}$ in the northeastern Dali-nor Lake, is influenced visibly by groundwater recharge and again evaporation process. Relatively, the deep water area, which depth is deeper than $8 \mathrm{~m}$ in the southwestern Dali-nor Lake, is scarcely influenced by the revalorizations, and the bottom water mass is more stable and longer residence time than that in shallow region.

Keywords: $\delta \mathrm{D}$ and $\delta^{18} \mathrm{O}$; distribution; lake water; recharge characteristics; Dali-nor Lake

湖泊是重要的地表水资源库, 作为汇水盆地和陆地生态系统的一部分, 不仅参与了 “水一陆一气” 相互作 用过程,也是区域水文循环的关键节点,湖泊水体的补一排循环过程不仅能够充分记录湖区水文循环特征, 而且会对区域生态环境等演变产生影响 ${ }^{[1-7]}$. 近年来,作为水体主要组成部分的氢、氧稳定同位素 $\left(\delta \mathrm{D} 、 \delta^{18} \mathrm{O}\right)$ 已经被广泛应用到湖泊补一排特征等水文循环过程研究中 ${ }^{[8-9]}$. 通过对不同水体 $\delta \mathrm{D} 、 \delta^{18} \mathrm{O}$ 值变化分析, 可以 了解来源水体特性、主要影响因素等信息,进而建立流域不同水体间 $\delta \mathrm{D} 、 \delta^{18} \mathrm{O}$ 的相互关系,据此可判断不同 水体间的变化过程 ${ }^{[10-12]}$. 自二十一世纪初期以来, Ohba、Gibson、Biggs 等就对湖泊水文循环过程中 $\delta \mathrm{D} 、 \delta^{18} \mathrm{O}$ 值的变化进行分析研究, 建立了相应的湖泊水量平衡方程 ${ }^{[13-16]}$; 在国内, 陈建生、章新平、姚檀栋等也已经广 泛开展了青藏高原、内陆沙漠等区域不同水体中 $\delta \mathrm{D} 、 \delta^{18} \mathrm{O}$ 值变化过程的分析研究 ${ }^{[17-20]}$. 不过, 相对于其他区 域, 中国内蒙古高原寒早区气候变化存在蒸发作用强烈、冬季结冰期漫长等显著的区域气候环境特征 ${ }^{[4,21]}$, 这导致面状存在的湖泊排泄一补给过程在不同季节会遭受不同气候因素的影响. 例如, 夏季, 集中的大气降 水不断补给湖水, 水体交换相对较快; 冬季, 湖面被厚层湖冰覆盖, 一定程度上阻隔了湖水与大气等外界系 统的交换, 湖水受蒸发作用的影响相对减弱, 补给过程主要受区域地下水输人的影响, 湖水性质整体相对稳 定; 春、秋季, 大气降水明显减少, 湖水受到地下水补给的同时又受到强烈蒸发作用的影响, 湖泊水体呈减少 趋势 ${ }^{[21]}$. 因此, 显著的区域气候水文特征也使内蒙古高原内陆封闭型湖泊成为分析寒旱区湖泊地下水补给 区域特征的理想目标.

由此, 本文将以内蒙古中东部赤峰市克什克腾旗境内的达里诺尔湖 ( 以下简称 “达里湖”) 为研究目标 区域, 在前期对达里湖流域不同水体间补排关系初步判定和对开放条件下达里湖水体垂向结构变化的具体 分析基础上 ${ }^{[22-23]}$, 将通过夏、冬季湖泊底层、表层水 (冰) 及人湖河水、区域浅层地下水 (泉水、井水) 等样品 的连续采集, 综合对比不同样品 $\delta \mathrm{D} 、 \delta^{18} \mathrm{O}$ 含量变化, 对达里湖冬季底层水体 $\delta \mathrm{D} 、 \delta^{18} \mathrm{O}$ 值的空间分布特征及 主要影响因素展开深人分析,为寒旱区封闭型湖泊的水文循环过程研究提供理论参考.

\section{1 达里湖概况}

达里湖 ( $43^{\circ} 12^{\prime} \sim 43^{\circ} 24^{\prime} \mathrm{N}, 116^{\circ} 24^{\prime} \sim 116^{\circ} 56^{\prime} \mathrm{E}$ ) 是中国北方寒早区典型的高原内陆湖泊, 湖水无河流作 用外泄. 达里湖水体的主要补给来源为大气降水、人湖河流及地下水等 ${ }^{[24]}$. 目前, 共有亮子河、沙里河、耗来 河与贡格尔河等 4 条河流输人达里湖 (图 1a), 其中亮子河与贡格尔河为主要人湖河流. 受降水量及季节交 替的影响, 河流年均输人湖泊的水量存在明显差异 ${ }^{[24]}$.

鉴于达里湖显著的区域气候特征, 虽然夏季相对集中的大气降水会补给到达里湖, 但湖面同时受到持 续蒸发作用的影响, 直至冬季湖面冰封. 因此达里湖水面面积及水深受季节交替的影响会出现一定幅度的 波动. 现有资料显示达里湖面积约为 $190 \mathrm{~km}^{2[25]}$. 通过以 2012-2016 年共 5 幅 Landsat 卫星影像为基础, 采 用彩色合成法和修改的归一化水体指数法两种水陆分离方法 ${ }^{[26]}$, 对达里湖水面面积变化特征进行信息提取 并对湖面面积进行计算, 结果显示达里湖的湖面面积虽然存在一定程度的年际变化, 不过 2016 年和 2012 年 湖面面积大小相似. 经计算, 2012- 2016 年, 达里湖水面面积平均约为 $189 \mathrm{~km}^{2}$, 年均变化范围约 $1 \%{ }^{[26]}$, 这 也与前人的研究成果基本一致 (图 $1 \mathrm{~b})^{[25]}$.

受湖泊面积变化的影响, 达里湖不同区域的湖水深度会出现一定程度的波动. 整体上,湖盆西南深、东北 浅, 湖水最深处约 $13 \mathrm{~m}^{[25-26]}$. 特别在达里湖西南侧湖水深度变化最明显, 形成显著的水下陡崖. 除西南部湖岸 坡度较大外, 达里湖其他区域湖岸均相对平缓, 水深逐渐变浅. 2013-2018 年不同采样点实测的水深平均值列 于表 1:DL-4、DL-6、DL-9、DL-11 及 DL-12 点的水深均超过 $8 \mathrm{~m}$, 而最北部的 DL-1 点的水深约为 $1.2 \mathrm{~m}$, 这些实 测水深数据验证了基于卫星图片数据反演的湖泊水深特征. 当然, 虽然与前人得出的湖泊水深整体变化趋势 
一致,但具体深度及分布范围却存在一定程度的差异, 这可能和近年湖泊整体水量的波动减少有关 $(\text { 图 } 1 \mathrm{~b})^{[25]}$.

\section{2 样品与方法}

基于达里湖区域地形地貌特征、现代水文地质条件以及人湖河流的河口位置等要素特征, 共在湖内布 设 12 个采样点 ${ }^{[21]}$, 依次命名为: DL-1、DL-2、DL-3、DL-4、DL-5、DL-6、DL-7、DL-8、DL-9、DL-10、DL-11、DL-12 (图 1、表 1), 其中 DL-1、DL-5、DL-10、DL-11 等站点依据河口位置布设. 样品主要为冬季( 2016 年 1 月、2017 年 1 月、2018 年 1 月)所采集的湖泊底层水、表层水(冰)、入湖河流、浅层地下水及夏季(2015 年 $8 、 9$ 月)湖 水等, 同时参考部分已发表的大气降水等数据 ${ }^{[22]}$. 具体采样方法为: 冬季需要开丵湖冰后再进行样品采集, 共采集冰、水样 3 次, 其中底层水和表层水 (水深约 $0 \sim 20 \mathrm{~cm}$ ) 样品每次采集 24 个,共 72 个. 湖冰分为上、 中、下 3 层采集, 每次采集 36 个, 共采集 108 个; 夏季湖泊水样利用船舶直接在采样点进行采集, 根据各站点 具体位置及水深变化情况, 夏季湖水采样 2 次, 采集底层水和表层水样品共计 48 个; 采集人湖河水及井水等 浅层地下水样品共计 30 个. 根据实际测试所需样品量, 每次采集 $50 \sim 100 \mathrm{ml}$, 需要注意的是采集后需立即密 封保存在聚乙烯瓶中, 并尽快完成测试工作, 以免造成二次蒸发分馏.
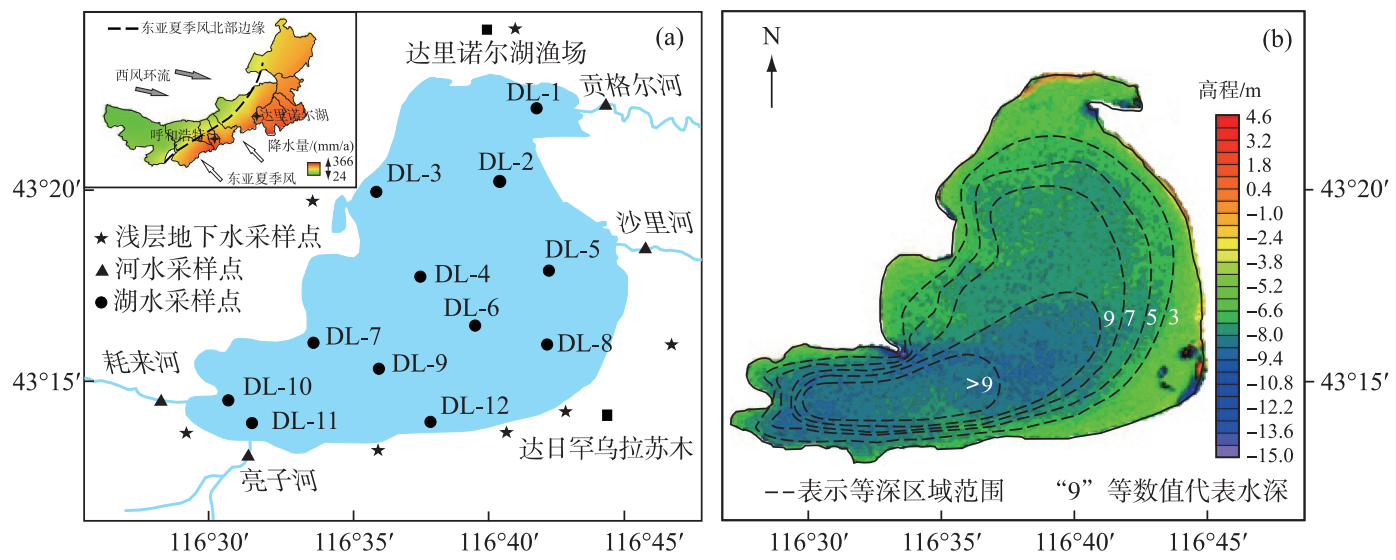

图 1 达里湖采样点分布及现代水深变化特征: (a) 达里湖采样点位置分布示意图;

(b) 遥感数据反演的湖水深度及根据参考文献 [25]改绘的湖水深度变化示意图

Fig.1 Locations of sample sites and water depth change in Dali-nor Lake

水体样品中 $\delta \mathrm{D} 、 \delta^{18} \mathrm{O}$ 值采用美国 Los Gatos Research(LGR) 公司生产的液态水同位素分析仪进行测定. 样品在分析测试之前需要经过 $0.45 \mu \mathrm{m}$ 的滤膜过滤 $3 \sim 4$ 次, 每一样品测试 6 次, 取后 4 次的平均值. 样品测 试结果均经过国际原子能机构 (International Atomic Energy Agency, IAEA) 的 VSMOW (Vienna Standard Mean Ocean Water) 标准样品进行校正. 测试精确度: $\delta^{18} \mathrm{O}$ 误差小于 $0.1 \%, \delta \mathrm{D}$ 误差小于 $0.4 \%$ （高精度测量模式下 的标定).

$$
\delta(\% 0)=\frac{R_{\text {样品 }}-R_{\text {标准样品 }}}{R_{\text {标准样品 }}} \times 1000
$$

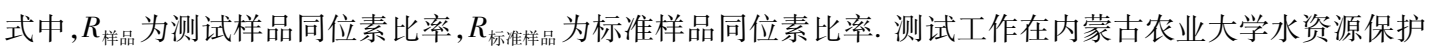
与利用自治区重点实验室完成.

\section{3 结果与讨论}

\section{1 达里湖区域不同水体样品中 $\delta D$ 和 $\delta^{18} O$ 值相互关系变化特征}

水体所处的区域环境不同会导致其 $\delta \mathrm{D} 、 \delta^{18} O$ 值也存在差异, 这一特征使得水体中 $\delta \mathrm{D} 、 \delta^{18} O$ 值成为重要 的环境指标, 已被广泛应用到湖泊河流等区域水循环的研究中 ${ }^{[27-30]}$. 通过不同水体样品中 $\delta \mathrm{D} 、 \delta^{18} \mathrm{O}$ 值变化 特征及相互关系分析, 可以了解达里湖区域水文循环过程及潜在的影响因素 ${ }^{[31-32]}$. 同时, 达里湖表层水主要 
受到大气降水和蒸发作用的影响, 而湖泊底层水所 处环境相对封闭,水体 $\delta \mathrm{D} 、 \delta^{18} 0$ 值的变化则主要受 地下水补给及湖水垂向迁移交换过程的影响 ${ }^{[22,33]}$. 因此, 通过对比分析达里湖表层一底层水间 $\delta \mathrm{D} 、 \delta^{18} \mathrm{O}$ 值的差异, 将有助于理解不同外界条件下达里湖表、 底层水间稳定同位素组成的变化规律. 此外, 由于冬 季达里湖上部水体分为湖冰和冰下水体两种形态, 在数据分析对比过程中, 将各采样点处的湖泊冰体 和冰下水体 (即冬季湖泊表层水) 中的 $\delta \mathrm{D} 、 \delta^{18} \mathrm{O}$ 值 进行平均处理,然后再和底层水进行对比分析.

首先, 达里湖区湖水和浅层地下水 (以湖区井 水、泉水为代表)、河水的 $\delta \mathrm{D}$ 和 $\delta^{18} \mathrm{O}$ 值分别位于区 域“大气水线” ${ }^{\left[{ }^{34-35]}\right.}$ 的两侧, 整体差异明显; 而达里 湖表层水体 (包括夏季和冬季) 和底层水体中稳定 同位素的相互关系差异不大, 分别为 $\delta \mathrm{D}=3.23 \delta^{18} \mathrm{O}-$ 25.36 和 $\delta D=3.41 \delta^{18} O-25.04$, 且 $\delta D 、 \delta^{18} O$ 值均位于 区域“大气水线”的下方 (图 2), 显示湖泊水体受到 蒸发作用的影响 ${ }^{[34]}$. 具体来讲, 夏季, 湖泊表层水体 $\delta \mathrm{D} 、 \delta^{18} \mathrm{O}$ 值 $(-1.99 \%$ 、 $-32.61 \%)$ 比底层水体 $\delta \mathrm{D}$ 、 $\delta^{18} \mathrm{O}$ 值 $(-2.13 \%$ 、 $-32.95 \%$ ) 略微偏正 (表 2); 冬季, 如不包括上覆湖冰, 表层水体中 $\delta \mathrm{D} 、 \delta^{18} \mathrm{O}$ 值 $(-2.51 \% 0,-32.77 \% 0)$ 则比底层水体中 $\delta \mathrm{D} 、 \delta^{18} \mathrm{O}$ 值 $(-2.05 \%$ 。 $-31.51 \%$ ) 偏负 (表 2$)$. 当然,这一差异是 由于结冰过程对冰下表层水体 (即冬季表层水体) $\delta \mathrm{D} 、 \delta^{18} \mathrm{O}$ 值产生稀释影响导致的 ${ }^{[21]}$ : 结冰过程导致 的同位素分馏作用会引起冰体 $\delta \mathrm{D} 、 \delta^{18} \mathrm{O}$ 值明显偏正 $(-1.17 \%$ 。 $-25.48 \%$ ，表 2$)$, 而冰下水体中的 $\delta \mathrm{D} 、 \delta^{18} \mathrm{O}$ 值 $(-2.51 \%$ 、 $-32.77 \%$ ) 则相应地出现偏负变化. 此 外, 相对于湖泊水体, 浅层地下水和人湖河水 $\delta \mathrm{D}$ 、 $\delta^{18} \mathrm{O}$ 值不仅明显偏负, 而且受季节变化影响更加 明显: 夏季浅层地下水和河水的 $\delta D 、 \delta^{18} O$ 值 $(-13.32 \%$ 。 $-86.90 \%)$ 均比冬季浅层地下水和河水 的同位素值 $(-12.22 \%$ 、 $-80.85 \%$ ) 偏负 (表 2 ), 同时 浅层地下水 $\delta \mathrm{D} 、 \delta^{18} \mathrm{O}$ 值位于区域 “大气水线” 以上 (图 2), 显示受二次蒸发作用的影响明显比湖水 弱 ${ }^{[17]}$. 当然,综合比较可以发现大气降水 $\delta \mathrm{D} 、 \delta^{18} \mathrm{O}$ 平

均值 $(-7.34 \% \text { 、 }-53.58 \%)^{[34]}$ 介于湖泊水体和浅层地下水及人湖河水 $\delta \mathrm{D} 、 \delta^{18} \mathrm{O}$ 平均值之间 (表 2), 显示了大 气降水在达里湖区域水文循环过程中的承接作用 ${ }^{[34-35]}$.

其次, 在夏季,达里湖表层水与底层水中 $\delta \mathrm{D}$ 和 $\delta^{18} \mathrm{O}$ 平均值的差异并不大, 表层水 $\delta \mathrm{D} 、 \delta^{18} \mathrm{O}$ 平均值略重 于底层水 (图 3 和表 2). 虽然夏季湖面处于相对开放的环境下, 大气降水会带来稳定同位素值偏负的水体, 但是开放的湖面环境同时非常有利于蒸发作用的进行, 大气降水量一旦有所下降, 蒸发作用引起的同位素 浓缩效应往往会抵消大气降水对湖泊表层水中同位素稀释变化的影响 ${ }^{[23,34]}$. 相对地, 湖泊底层水不仅受大 气降水的直接影响较弱,而且又会持续接收偏轻地下水的补给 ${ }^{[22]}$. 因此,夏季表层水与底层水间受到不同 因素的影响, 导致达里湖夏季表层水中 $\delta \mathrm{D} 、 \delta^{18} \mathrm{O}$ 平均值比底层水平均值略偏正 (图 3). 虽然, 夏季达里湖个 各采样点平均水深 ${ }^{[23]}$

Tab.1 Average water depth at each sample location between 2013 and 2018 in Dali-nor Lake ${ }^{[23]}$

\begin{tabular}{cccc}
\hline 站点名称 & 经度 $^{\circ}$ & 纬度 $^{\circ}$ & 平均水深 $/ \mathrm{m}$ \\
\hline DL-1 & 116.6959 & 43.3708 & 1.2 \\
DL-2 & 116.6333 & 43.3502 & 7.1 \\
DL-3 & 116.5987 & 43.3326 & 6.2 \\
DL-4 & 116.6329 & 43.3005 & 8.2 \\
DL-5 & 116.7223 & 43.3000 & 7.0 \\
DL-6 & 116.5667 & 43.2833 & 8.3 \\
DL-7 & 116.5619 & 43.2601 & $7.5(0.7)^{*}$ \\
DL-8 & 116.6669 & 43.2667 & 6.0 \\
DL-9 & 116.5900 & 43.2501 & 8.8 \\
DL-10 & 116.5012 & 43.2386 & 7.4 \\
DL-11 & 116.5169 & 43.2369 & 9.0 \\
DL-12 & 116.6339 & 43.2356 & 8.6
\end{tabular}

* 表示实际采样过程中, 由于 DL-7 采样点受到湖底沙脊的影 响, 导致冬季和夏季具体的取样位置存在偏移,冬季采样点水 深平均约为 $7.5 \mathrm{~m}$,夏季采样点水深则约为 $0.7 \mathrm{~m}$.

表 2 达里湖不同水体稳定同位素平均值

Tab.2 Average values of stable isotopes in different water samples of Dali-nor Lake

\begin{tabular}{cccccc}
\hline & \multicolumn{2}{c}{ 冬季 } & & \multicolumn{2}{c}{ 夏季 } \\
\cline { 2 - 3 } \cline { 5 - 6 } & $\delta^{18} \mathrm{O} / \%$ & $\delta \mathrm{D} / \% 0$ & & $\delta^{18} \mathrm{O} / \% 0$ & $\delta \mathrm{D} / \% 0$ \\
\hline 浅层地下水 & -12.22 & -80.85 & -13.32 & -86.90 \\
河水 & -10.80 & -81.42 & -12.42 & -81.60 \\
大气降水 & - & - & & -7.34 & -53.58 \\
湖泊冰体 & -1.17 & -25.48 & - & - \\
表层水 & -2.51 & -32.77 & & -1.99 & -32.61 \\
底层水 & -2.05 & -31.51 & -2.13 & -32.95 \\
湖冰+表层水体 & -1.84 & -29.12 & - & - \\
\hline
\end{tabular}

一代表无有效数据; * 数据来自参考文献 $[34]$; ※表层水 包含夏季湖泊上层水体和冬季湖泊表层水体 (但不含上 覆冰体).
表 1 达里湖 2013-2018 年以来 


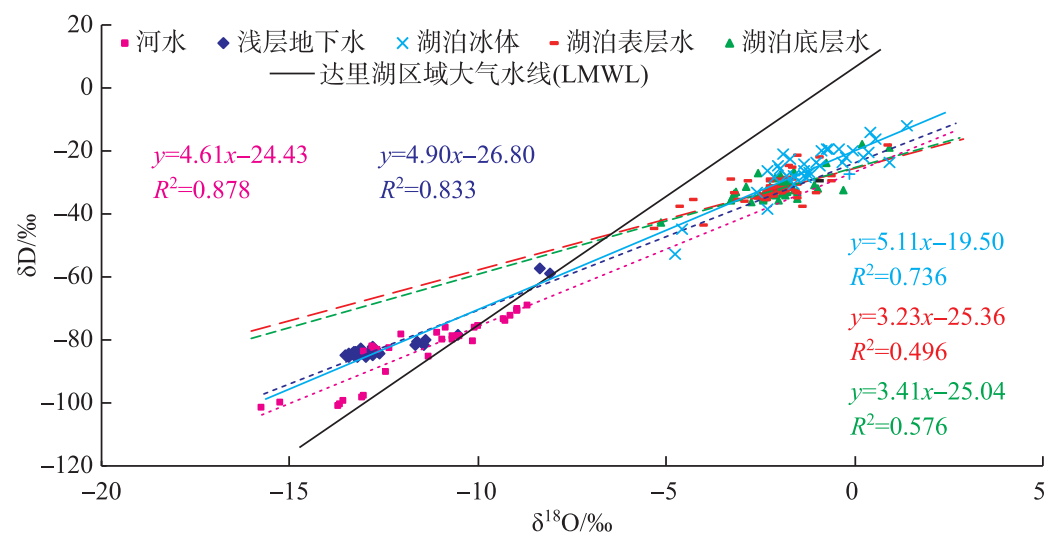

图 2 达里湖不同水体中 $\delta \mathrm{D}$ 和 $\delta^{18} \mathrm{O}$ 值变化关系

(图中 LMWL 表示达里湖区域“大气水线”,关系式为 $\delta \mathrm{D}=8.26 \delta^{18} \mathrm{O}-7.21\left(R^{2}=0.9030\right.$, $n=42$ )，数据来源于文献 [34]，图中各个公式中“ $y$ ”均代表“ $\delta \mathrm{D}$ ”,而“ $x$ ”代表“ $\delta^{18} \mathrm{O}$ ” )

Fig. 2 Relationships of $\delta \mathrm{D}$ and $\delta^{18} \mathrm{O}$ in different water samples

别采样点湖水 $\delta \mathrm{D} 、 \delta^{18} \mathrm{O}$ 值存在一定程度的偏移 (如 DL-4 点), 但整体上可以说夏季表层湖水的稳定同位素 组成相对稳定, 区域差异不大 (图 3). 而在冬季, 如果仅仅考虑数值的变化, 那么达里湖底层水和冰下湖水 的表层水中的稳定同位素值差异并不明显, 甚至表层水中 $\delta \mathrm{D} 、 \delta^{18} \mathrm{O}$ 平均值要比底层水中 $\delta \mathrm{D} 、 \delta^{18} \mathrm{O}$ 平均值偏 轻 (表 2). 具体到各个采样点, 则只有 DL-1、DL-3 和 DL-6 点处的表层水中 $\delta \mathrm{D} 、 \delta^{18} 0$ 值比底层水偏重. 不过, 一旦考虑到结冰过程对同位素分馏过程的影响, 那么冬季冰体和冰下表层水中 $\delta \mathrm{D} 、 \delta^{18} \mathrm{O}$ 值的整体平均值 $(-1.84 \%$ 、 $-29.12 \%$ ) 则明显比底层水平均值 $(-2.05 \%$ 、- $31.51 \%$ ) 偏正 (图 3 和表 2 ). 特别地, 在各采样点 中, 只有位于河流人湖口处的 DL-1、DL-10、DL-11 点的表层水中 $\delta \mathrm{D} 、 \delta^{18} \mathrm{O}$ 值比底层水中的 $\delta \mathrm{D} 、 \delta^{18} \mathrm{O}$ 值偏负, 显示与河流输人稳定同位素值较轻的河水有关 ${ }^{[21]}$.

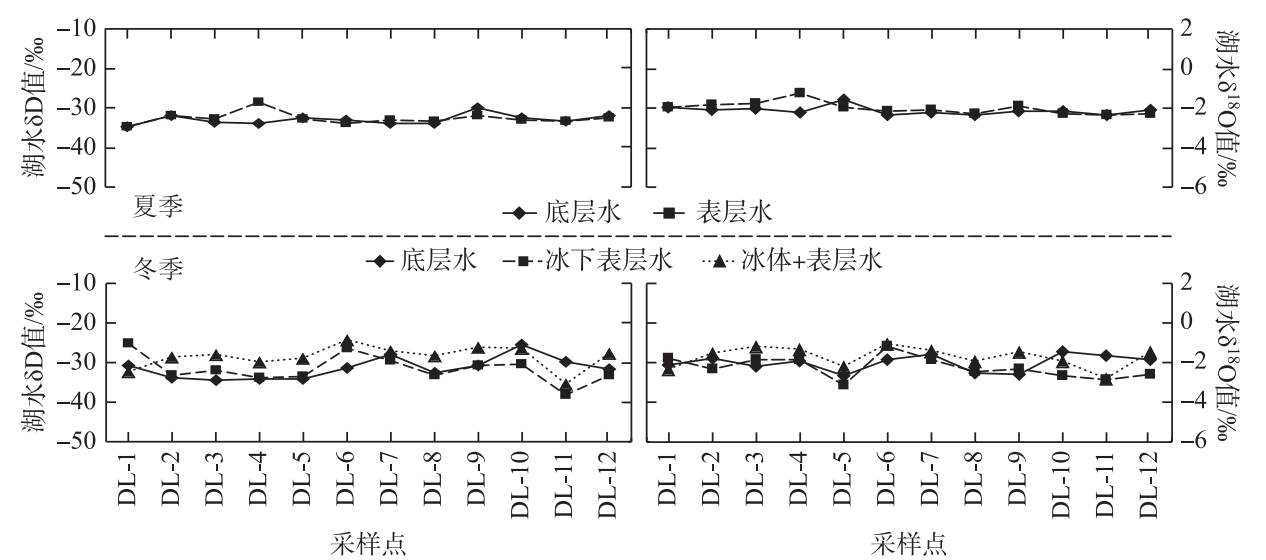

图 3 达里湖夏、冬季各采样点表层一底层水体中 $\delta \mathrm{D}$ 和 $\delta^{18} \mathrm{O}$ 值变化 (采样点间的连线不代表具体变化趋势)

Fig.3 Value changes of $\delta \mathrm{D}$ and $\delta^{18} \mathrm{O}$ in surface and bottom water in Dali-nor Lake in summer and winter

如果系统对比夏、冬季达里湖表层水(冰)体和底层水体中 $\delta \mathrm{D} 、 \delta^{18} \mathrm{O}$ 值变化特征, 可以发现冬季达里湖 水体稳定同位素值的区域差异性比夏季明显, 且底层水 $\delta \mathrm{D} 、 \delta^{18} \mathrm{O}$ 平均值相对稳定, 季节变化幅度要比表层 水小: 底层水中 $\delta \mathrm{D}$ 和 $\delta^{18} \mathrm{O}$ 值的冬、夏季节差异幅度为 $1.44 \%$ 和 $0.08 \%$, 明显低于表层水中 $2.49 \%$ 和 $0.15 \%$ 
的季节变化幅度 (图 3 和表 2). 对于表层水,不同季节会受到外界环境变化的差异影响: 夏季大气降水量一 旦有所下降, 蒸发作用导致的水体同位素的浓缩效应则会迅速显现; 冬季, 虽然蒸发作用被巨厚湖冰所阻 挡,但是结冰过程引起的同位素分馏同样使得表层水中稳定同位素值偏负. 这也成为影响表层水中 $\delta \mathrm{D} 、 \delta^{18} \mathrm{O}$ 值季节差异的主要因素 ${ }^{[21]}$. 相对地, 底层水所处环境相对封闭, 冬季一旦湖面冰封, 地下水的补给输人则成 为影响稳定 $\delta D 、 \delta^{18} O$ 组成的主要因素之一.

整体上, 达里湖流域不同水体中, 湖泊水体 (水、冰) 的 $\delta \mathrm{D} 、 \delta^{18} \mathrm{O}$ 平均值相对最偏正, 而浅层地下水和源 于地下水的人湖河流的 $\delta \mathrm{D} 、 \delta^{18} \mathrm{O}$ 平均值相对最偏负. 此外, 湖泊底层水 $\delta \mathrm{D} 、 \delta^{18} \mathrm{O}$ 值的冬、夏季节差异相对较 小. 当然, 由于受到不同季节气候环境条件差异的影响, 达里湖底层水和表层水(冰) 中 $\delta \mathrm{D} 、 \delta^{18} \mathrm{O}$ 平均值变化 往往出现波动. 例如, 夏季底层水中 $\delta \mathrm{D} 、 \delta^{18} \mathrm{O}$ 值比表层水中 $\delta \mathrm{D} 、 \delta^{18} \mathrm{O}$ 值偏负, 而冬季则偏正. 此外, 冬季不同 区域底层水间 $\delta \mathrm{D} 、 \delta^{18} \mathrm{O}$ 值差异幅度明显高于夏季, 不仅显示了底层水和表层水中 $\delta \mathrm{D} 、 \delta^{18} \mathrm{O}$ 组成特征的主要 影响因素存在差异,也为选择冬季讨论达里湖底层水中 $\delta \mathrm{D} 、 \delta^{18} \mathrm{O}$ 值分布区域差异提供了理论依据.

\section{2 冬季达里湖底层水 $\delta \mathrm{D}$ 和 $\delta^{18} \mathrm{O}$ 值的空间分布及影响因素}

基于不同水体及达里湖表、底层湖水中 $\delta \mathrm{D} 、 \delta^{18} \mathrm{O}$ 值变化特征的分析, 可以发现在冬季相对封闭 (湖水流 动速度非常缓慢, 不同区域间湖水交换几乎停滞 $\left.{ }^{[24]}\right)$ 条件下, 达里湖底层水体中 $\delta \mathrm{D} 、 \delta^{18} \mathrm{O}$ 值依然存在一定程 度的区域变化差异. 因此,利用 2016-2018 年共计 3 年冬季达里湖底层水体中 $\delta D 、 \delta^{18} O$ 值的区域变化记录 及氛盈余指数 $\left(d=\delta \mathrm{D}-8 \delta^{18} \mathrm{O}\right)^{[36-37]}$ 差异, 对可能影响达里湖底层水体 $\delta \mathrm{D} 、 \delta^{18} \mathrm{O}$ 值分布区域特征的地下水的 区域补给过程进行分析讨论.

虽然不同年份冬季达里湖底层水 $\delta \mathrm{D} 、 \delta^{18} \mathrm{O}$ 值的整体平均值相差不大, 显示了底层水中 $\delta \mathrm{D}$ 和 $\delta^{18} \mathrm{O}$ 值组 成的年际稳定特征. 但就各采样点来看, 由于具体位置的差异, 不同区域表现出明显的差异变化:位于湖泊 边缘 (或水深较浅的区域) 的采样点水体 $\delta \mathrm{D} 、 \delta^{18} \mathrm{O}$ 平均值多数要比整个达里湖的平均值偏负, 而位于湖泊西 南部 (或水深较深区域) 的采样点, 则多数比平均值偏正 (图 $4 a 、 b$ ). 整体上, 可以将冬季达里湖底层水中 $\delta \mathrm{D} 、 \delta^{18} \mathrm{O}$ 平均值分为两个主要区域: 以 DL-7、DL-9、DL-10、DL-11 采样点为代表的深水区 (水深超过 $8 \mathrm{~m}$ ), 其 底层水体的 $\delta \mathrm{D} 、 \delta^{18} \mathrm{O}$ 平均值比全湖平均值偏正且 $d$ 值多数偏负 (图 4a、c); 以 DL-1、DL-2、DL-5 点为代表的 浅水区 (水深小于 $8 \mathrm{~m}$ ), 其底层水中 $\delta \mathrm{D} 、 \delta^{18} \mathrm{O}$ 平均值则比全湖平均值偏负且 $d$ 值多数偏正 (图 $4 \mathrm{~b} 、 \mathrm{c}$ ). 显 然, 湖水深度的变化对水体稳定同位素的变化及分布特征产生了一定程度的影响, 这也显示深水区和浅水 区底层水中 $\delta \mathrm{D} 、 \delta^{18} \mathrm{O}$ 值变化影响因素可能存在差异. 当然, 除此之外, 由于地理位置等特殊性, 如位于河流 人湖口附近的 DL-1、DL-10 等采样点, 其水体稳定同位素值会受到河水输人量的影响, 导致 $\delta \mathrm{D} 、 \delta^{18} \mathrm{O}$ 值出现 明显的波动 ${ }^{[21]}$ (图 4).

为了讨论达里湖底层水体中稳定同位素分布的区域差异, 在不同采样点底层水 $\delta \mathrm{D} 、 \delta^{18} \mathrm{O}$ 值和达里湖水 体整体 $\delta \mathrm{D} 、 \delta^{18} \mathrm{O}$ 平均值间差异 $\left(\Delta \delta \mathrm{D}\right.$ 和 $\left.\Delta \delta^{18} \mathrm{O}\right)$ 特征分析及结合指示水体受再蒸发作用影响程度强弱的 $d$ 值 变化的基础上 (图 4), 对不同区域采样点 $\Delta \delta \mathrm{D} 、 \Delta \delta^{18} \mathrm{O}$ 及 $d$ 值与水体深度间的相互关系进行了分析 (由于个 别站点受到河流输人等外界因素的影响明显, 如 DL-1 点等, 因此在相关性分析过程中不再考虑), 结果初步 显示了达里湖水深变化的确会对底层水中 $\delta \mathrm{D} 、 \delta^{18} \mathrm{O}$ 值的分布特征产生影响.

在深水区即底层水稳定同位素值偏正区域(图 $4 \mathrm{~d}$ ), 不同采样点 $\Delta \delta^{18} \mathrm{O} 、 \Delta \delta \mathrm{D}$ 及 $d$ 值均和湖水深度变化 显示了良好的相关性, 相关系数 $r$ 值均不低于 0.60 , 分别为 $0.80 、 0.60$ 和 0.84 (图 5a); 而在浅水区即底层水 稳定同位素值偏负区域 (图 4d), 3 个指标和水体深度变化的相互关系相对较差, 相关系数 $r$ 值均低于 0.60 , 分别为 $0.49 、 0.49$ 和 0.56 (图 $5 \mathrm{~b}$ ). 显然, 水深变化和水体稳定同位素分布特征之间存在一定程度的相关性. 再者, 在深水区, $\Delta \delta^{18} \mathrm{O} 、 \Delta \delta \mathrm{D}$ 及 $d$ 值 3 个指标参数和水深变化均呈负相关, 说明水深越深, 底层水体中 $\delta^{18} \mathrm{O}$ 、 $\delta \mathrm{D}$ 值相对于全湖平均值就越偏正. 在浅水区, $\Delta \delta^{18} O 、 d$ 值与水体深度变化同样显示负相关关系, 不过 $\Delta \delta \mathrm{D}$ 值和水深变化却呈现出正相关变化. 当然, 由于浅水区各指标参数变化与水深变化的相关系数均低, 因此具 体的变化趋势有待进一步分析.

达里湖冬季呈现半封闭状态, 湖面被厚层的湖冰覆盖, 河流和地下水成为湖泊水体交换的主要途径. 不 过, 4 条人湖河流在冬季同样会被河冰覆盖, 人湖流量明显减少甚至断流, 冬季人湖河流河口采样点底层水 体的 $\delta^{18} \mathrm{O} 、 \delta \mathrm{D}$ 值明显比夏季偏正, 这显示了河流输人对湖泊水体影响减弱 ${ }^{[23]}$. 因此, 冬季湖水和地下水间的 

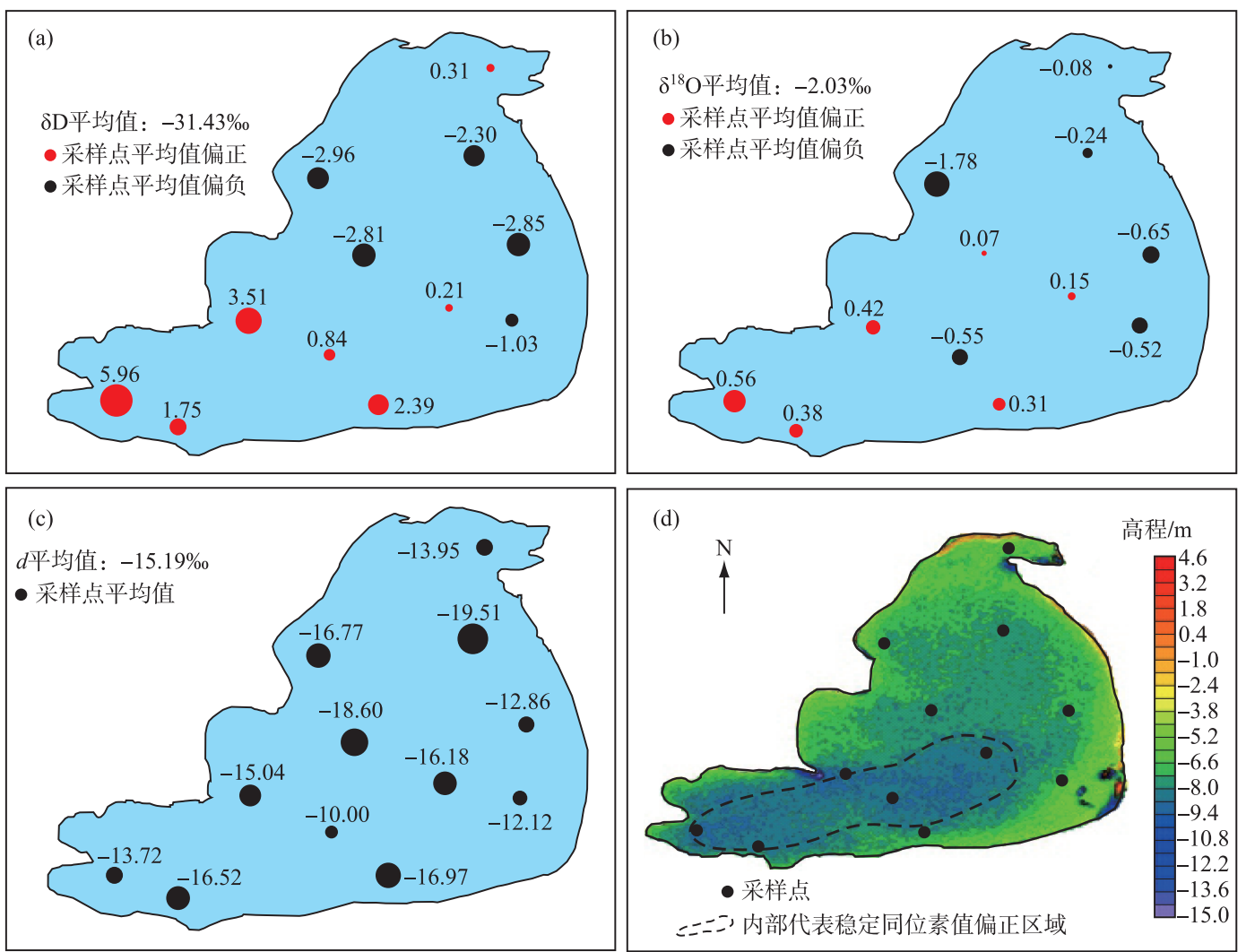

图 $42016-2018$ 年冬季达里湖底层水体中 $\delta D 、 \delta^{18} \mathrm{O}$ 及氝盈余指数 $d$ 平均值的区域变化特征: (a) 冬季达里湖各采样点底层水 $\delta \mathrm{D}$ 值与全湖平均值之间 $\Delta \delta \mathrm{D}$ 的空间分布; (b) 冬季达里湖各采样点底层水 $\delta^{18} \mathrm{O}$ 值与全湖平均值之间 $\Delta \delta^{18} \mathrm{O}$ 的空间分布; (c) 冬季达里湖各采样点底层水氝盈余指数 $d$ 值的空间分布;

(d) 达里湖底层水体 $\delta \mathrm{D} 、 \delta^{18} \mathrm{O}$ 值变化的区域性 $\left(\right.$ 氝盈余指数 $\left.\left(d=\delta \mathrm{D}-8 \delta^{18} \mathrm{O}\right)^{[36-37]}\right)$

Fig.4 Distribution characteristics of $\delta \mathrm{D}, \delta^{18} \mathrm{O}$ and $d$-excess average values in winter bottom water of Dali-nor Lake during 2016 and 2018

交换往往成为影响湖泊底层水体稳定同位素组成的主要因素. 根据 $d$ 值和水深的关系, 可以看出水深越深, $d$ 值越偏负 (图 5), 而 $d$ 值偏负则说明水体受到二次蒸发程度越弱 ${ }^{[38-39]}$. 显然, 水越深的区域, 其底层水受到 二次蒸发作用影响的可能性越小. 相对地, 浅水区域由于受到湖岸区域浅层地下水的直接补给可能性较大 且水体 $d$ 值相对偏正, 显然浅水区更容易受二次蒸发作用的影响. 此外, 冬季深水区域采样点水体 $\delta^{18} \mathrm{O} 、 \delta \mathrm{D}$ 值均比浅水区域采样点水体 $\delta^{18} O 、 \delta \mathrm{D}$ 值偏正, 从一方面说明深水区域底层水稳定同位素组成受到 $\delta^{18} O 、 \delta \mathrm{D}$ 平均值偏负浅层地下水的稀释作用更弱一些; 另一方面, 相对于浅水区, 深水区底层水所处的环境更加封 闭, 底层水的补排过程可能更加缓慢, 水体保留时间更长, 更加稳定 (沉积物的 $\mathrm{AMS}-{ }^{14} \mathrm{C}$ 测年结果显示达里 湖存在约 400 600 a 的碳库效应 ${ }^{[40]}$, 也从一方面证明了上述论断), 这也是导致水深越深, 底层湖水 $\delta^{18} \mathrm{O}$ 和 $\delta \mathrm{D}$ 值越偏正的关键因素之一.

总之, 在达里湖, 东北部水体较浅的采样点水体 $\delta \mathrm{D} 、 \delta^{18} \mathrm{O}$ 平均值多数比湖水整体平均值偏负且 $d$ 值偏 正, 显示区域浅层地下水输人及二次蒸发作用的影响明显; 而西南部水深较深的采样点水体 $\delta \mathrm{D} 、 \delta^{18} \mathrm{O}$ 平均 值多数比达里湖整体平均值偏正且 $d$ 值偏负, 显示了与浅水区域不同的补给特征, 即深水区底层水相对稳 定, 水体受二次蒸发作用的影响较弱. 整体上, 水深变化成为影响达里湖底层水体稳定同位素分布特征及水 体补给过程的关键因素之一. 
(a)

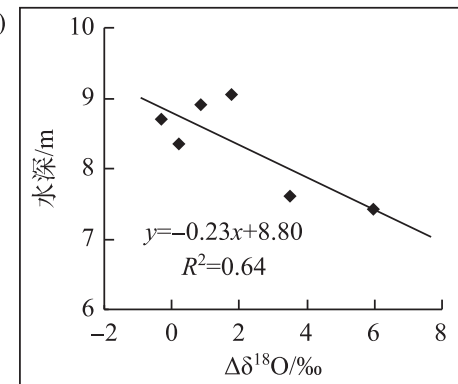

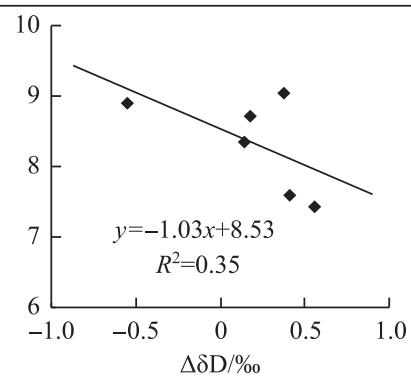

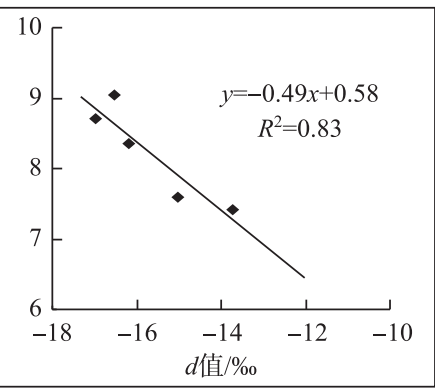

(b)
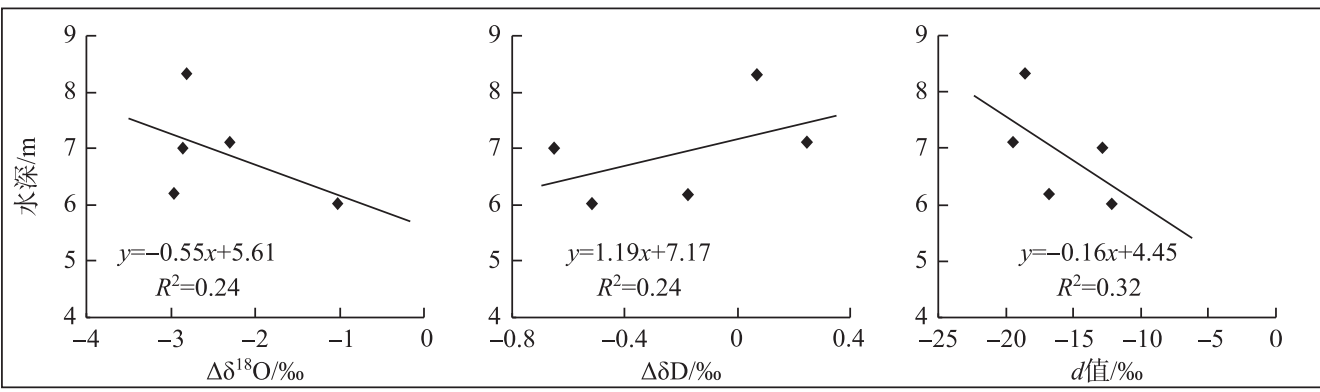

图 5 达里湖底层水体中稳定同位素及 $d$ 值和水深变化的相互关系: (a) 深水区; (b) 浅水区 $\left(\Delta \delta^{18} \mathrm{O}\right.$ 和 $\Delta \delta \mathrm{D}$ 为各采样点水体中 $\delta \mathrm{D} 、 \delta^{18} \mathrm{O}$ 值和全湖水体 $\delta \mathrm{D} 、 \delta^{18} \mathrm{O}$ 平均值的差值.

$R^{2}$ 为相关系数 $r$ 值的平方, 如 $R^{2}=0.64$, 则 $r$ 值为 0.8 . 氝盈余指数 $\left.\left(d=\delta \mathrm{D}-8 \delta^{18} \mathrm{O}\right)^{[36-37]}\right)$

Fig.5 Relationships between water depth change and stable isotope and $d$-excess value changes in bottom water with different depths in Dali-nor Lake: (a) deep water area; (b) shallow water area

\section{4 结论}

基于内蒙古寒旱区达里湖无河流外泄、冬季湖面冰封、水体流动缓慢等典型水文气象特征, 对达里湖表 层水、底层水、人湖河水及浅层地下水样品中 $\delta \mathrm{D} 、 \delta^{18} \mathrm{O}$ 值进行综合分析, 并据此讨论了底层水 $\delta \mathrm{D} 、 \delta^{18} \mathrm{O}$ 值的 区域差异和湖水深度变化的相互关系,主要结论如下:

1) 达里湖流域不同水体中, 湖泊水体 (水体和冰体) 的稳定同位素组成相对偏正, 而浅层地下水和源于 地下水的人湖河流的稳定同位素组成相对偏负. 对于达里湖水体, 冬季底层水体中 $\delta \mathrm{D} 、 \delta^{18} \mathrm{O}$ 值 $(-31.51 \%$ 、 $-2.05 \% 0)$ 比上层水体中 $\delta \mathrm{D} 、 \delta^{18} \mathrm{O}$ 值 $(-32.77 \% 0,-2.51 \% 0)$ 偏正, 而比冰体和上层水体中 $\delta \mathrm{D} 、 \delta^{18} \mathrm{O}$ 的平均值 $(-29.12 \% 0,-1.84 \% 0)$ 偏负; 夏季底层水体中 $\delta \mathrm{D} 、 \delta^{18} \mathrm{O}$ 值 $(-32.95 \%$ 、 $2.13 \%)$ 同样比上层水体中 $\delta \mathrm{D} 、 \delta^{18} \mathrm{O}$ 值 $(-32.61 \%$ 、 $-1.99 \%$ ) 偏负. 整体上, 冬季达里湖底层水体稳定同位素值的季节变化幅度比表层水体小, 区域 差异也比夏季更明显, 反映了底层水体相对稳定的储存环境和补给过程的区域差异特征.

2) 湖水深度变化是影响达里湖不同区域底层水稳定同位素分布差异的关键因素之一:在西南部深水区 (水深大于 $8 \mathrm{~m}$ ), 不同采样点水体 $\delta \mathrm{D} 、 \delta^{18} \mathrm{O}$ 值与全湖平均值间的差值 $\left(\Delta \delta^{18} \mathrm{O}\right.$ 和 $\left.\Delta \delta \mathrm{D}\right)$ 及 $d$ 值均和湖水深度 变化显示了良好的相关性,相关系数 $r$ 分别为 $0.80 、 0.60$ 和 0.84 ; 而在东北部浅水区 (水深小于 $8 \mathrm{~m}$ ), , 3 个指 标和水体深度变化的相互关系较差, 相关系数 $r$ 分别为 $0.49 、 0.49$ 和 0.56 . 整体上, 浅水区各采样点水体 $\delta \mathrm{D}$ 、 $\delta^{18} \mathrm{O}$ 平均值偏负且 $d$ 值偏正, 显示地下水输人及二次蒸发作用的影响明显; 而深水区采样点水体 $\delta \mathrm{D} 、 \delta^{18} \mathrm{O}$ 平均值多数比达里湖整体平均值偏正且 $d$ 值偏负, 即显示了与浅水区域不同的补给特征, 也说明深水区底 层水相对稳定,水体受二次蒸发作用的影响较弱.

\section{5 参考文献}

[ 1 ] Hu JR, Jiang FQ, Wang YJ et al. On the Importance of research on the lakes in arid land of China. Arid Zone Research, 
2007, 24(2) : 137-140. [胡汝瞕, 姜逢清, 王亚俊等. 论中国干旱区湖泊研究的重要意义. 干旱区研究, 2007, 24 (2) : 137-140.]

[ 2 ] Yang GS, Ma RH, Zhang L et al. Lake status, major problems and protection strategy in China. J Lake Sci, 2010,22 (6) : 799-810. DOI: 10.18307/2010.0601. [杨桂山, 马荣华, 张路等. 中国湖泊现状及面临的重大问题与保护策 略. 湖泊科学, $2010,22(6): 799-810$. ]

[ 3 ] An CB, Chen FH. The pattern of Holocene climate change in the arid central Asia: a case study based on lakes. $J$ Lake $S c i, 2009,21(3)$ : 329-334. DOI: 10.18307/2009.0303. [安成邦, 陈发虎. 中东亚干旱区全新世气候变化的西风模 式一以湖泊研究为例. 湖泊科学, 2009, 21(3): 329-334.]

[ 4 ] Hepp J, Tuthorn M, Zech R et al. Reconstructing lake evaporation history and the isotopic composition of precipitation by a coupled $\delta^{18} \mathrm{O}-\delta^{2} \mathrm{H}$ biomarker approach. Journal of Hydrology, 2014, 519: 2164-2173. DOI: 10.1016/j. jhydrol.2014. 10.012 .

[ 5 ] Qin BQ. A preliminary investigation of lake evolution in 20-century in inland mainland Asia with relation to the global warming. J Lake Sci , 1999, 11 (1) : 11-19. DOI: 10.18307/1999.0102. [秦伯强. 近百年来亚洲中部内陆湖泊演变及其 原因分析. 湖泊科学, 1999, 11(1): 11-19.]

[ 6 ] Gu XH, Mao ZG, Ding HP et al. Progress and prospect of lake fishery in China. J Lake Sci, 2018, 30(1): 1-14. DOI: 10.18307/2018.0101. [谷孝鸿, 毛志刚, 丁慧萍等. 湖泊渔业研究: 进展与展望. 湖泊科学, 2018, 30(1): 1-14.]

[ 7 ] Williams WD. Chinese and Mongolian saline lakes: a limnological overview. Hydrobiologia, 1991, 210(1/2) : 39-66. DOI: $10.1007 / \mathrm{BF} 00014322$.

[ 8 ] Qian H, Wu J, Zhou Y et al. Stable oxygen and hydrogen isotopes as indicators of lake water recharge and evaporation in the lakes of the Yinchuan Plain. Hydrological Processes, 2014, 28 (10) : 3554-3562. DOI: 10.1002/ hyp.9915.

[ 9 ] Ma HY, Zhao ZH, Wang D et al. Research progress of fractionation mechanism of stable hydrogen and oxygen isotope during water body evaporation. Advanced Materials Research, 2012, 550-553 : 2588-2592. DOI: 10.4028/www.scientific.net/ amr.550-553.2588.

[10] Zhang GL, Jiao YM, He LP et al. Hydrogen and oxygen isotopes in precipitation in Southwest China: progress and prospects. Journal of Glaciology and Geocryology, 2015, 37(4): 1094-1103. [张贵玲, 角媛梅, 何礼平等. 中国西南地区 降水氢氧同位素研究进展与展望. 冰川冻土, 2015, 37(4) : 1094-1103.]

[11] Zhu DN. Research on non-natural lakes based on isotope technology of chilly and arid region and hydro-geochemistry [Dissertation ]. Hohhot: Inner Mongolia Agricultural University, 2014. [ 朱冬楠. 基于同位素技术和水文地球化学的寒旱区 人工控制湖泊研究 [学位论文]. 呼和浩特: 内蒙古农业大学, 2014.]

[12] Wang SQ, Song XF, Xiao GQ et al. Appliance of oxygen and hydrogen isotope in the process of precipitation infiltration in the shallow groundwater areas of North China Plain. Advance Water Science, 2009, 20(4) : 495-501. [王仕琴, 宋献方, 肖国强等. 基于氢氧同位素的华北平原降水人渗过程. 水科学进展, 2009, 20(4): 495-501.]

[13] Ohba T, Hirabayashi J, Nogami. $\mathrm{D} / \mathrm{H}$ and ${ }^{18} \mathrm{O} /{ }^{16} \mathrm{O}$ ratios of water in the Crater Lake at Kusatsu-Shirane volcano, Japan. Journal of Volcanology \& Geothermal Research, 2000, 97(1) : 329-346. DOI: 10.1016/S0377- 0273(99)00169-9.

[14] Gibson JJ, Prowse TD, Peters DL. Hydroclimatic controls on water balance and water level variability in Great Slave Lake. Hydrological Processes, 2006, 20(16) : 4155-4172.

[15] Biggs TW, Lai CT, Candan P et al. Evaporative fractions and elevation effects on stable isotopes of high elevation lakes and streams in arid western Himalaya. Journal of Hydrology, 2015, 522(3) : 239-249.

[16] Gibson JJ, Birks SJ, Yi Y. Stable isotope mass balance of lakes: a contemporary perspective. Quaternary Science Reviews, 2016, 131: 316-328.

[17] Hu HY, Bao WM, Zai SM et al. Fractionation mechanism of stable hydrogen and oxygen isotope in water body evaporating. Journal of China Hydrology, 2007, 27 (6) : 1-5. [ 胡海英, 包为民, 翟思敏等. 稳定性氢氧同位素在水体蒸发中的研 究进展. 水文, 2007, 27(6): 1-5. ]

[18] Chen JS, Li L, Wang JY et al. Groundwater maintains dune landscape. Nature, 2004, 432: 459-460.

[19] Xiao W, Fu JR, Wang W et al. Estimating evaporation over a large and shallow lake using stable isotopic method: A case study of Lake Taihu. J Lake Sci, 2017, 29(4) : 1009-1017. DOI: 10.18307/2017.0425. [肖薇, 符靖茹, 王伟等. 用稳 定同位素方法估算大型浅水湖泊蒸发量一以太湖为例. 湖泊科学, 2017, 29(4) : 1009-1017.]

[20] Zhang XP, Yao TD. Estimation of lake evaporation by stable isotopic ratio. Journal of Glaciology and Geocryology, 1997, 19(2) : 161-167. [ 章新平, 姚檀栋. 利用稳定同位素比率估计湖泊的蒸发. 冰川冻土, 1997, 19(2) : 161-167.]

[21] Li WB, Li CY, Liu XX et al. Changes of stable oxygen and hydrogen isotopes and their responses to freezing process in Dali-nor lake in cold-arid areas of China. Earth Science-Journal of China University Geoscience, 2015, 40(12) : 2081-2090. [李文宝, 李畅游, 刘晓旭等. 寒旱区达里诺尔湖水体稳定氢、氧同位素变化对结冰过程的响应. 地球科学-地质大 
学学报, 2015, 40(12): 2081-2090.]

[22] Zhen ZL, Li CY, Li WB et al. Characteristics of environmental isotopes of surface water and groundwater and their recharge relationship in Lake Dali basin. J Lake Sci, 2014, 26(6) : 916-922. DOI: 10.18307/2014.0614. [ 甄志否, 李畅 游, 李文宝等. 内蒙古达里诺尔湖流域地表水和地下水环境同位素特征及补给关系. 湖泊科学, 2014, 26(6): 916-922.]

[23] Li WB, Liu ZJ, Yang X et al. Changes of stable oxygen and hydrogen isotopes in summer Dali-nor lake in Inner Mongolia of Northern China. J Lake Sci, 2019, 31(2) : 539-550. DOI: 10.18307/2019.0222. [李文宝, 刘志娇, 杨旭等. 内蒙 古高原达里诺尔湖夏季水体稳定同位素变化特征. 湖泊科学, 2019, 31(2): 539-550.]

[24] Liu ZJ. Tests of Hydrodynamics and hydrogen and oxygen stable isotopes in Lake Dalinuoer [Dissertation]. Hohhot: Inner Mongolia Agricultural University, 2015. [刘志娇. 达里诺尔湖水动力条件及氢氧稳定同位素试验研究 [学位论文]. 呼和浩特: 内蒙古农业大学, 2015.]

[25] Xiao JL, Si B, Zhai DY et al. Hydrology of Dali Lake in central-eastern Inner Mongolia and Holocene East Asian monsoon variability. Journal of Paleolimnology, 2008, 40(1) : 519-528.

[26] Wang XY. Research on the water depth retrieval of Dali Lake basing on 3S technology [Dissertation]. Hohhot: Inner Mongolia Agricultural University, 2017. [王旭阳. 基于 3S 技术的达里诺尔湖水深反演研究 [ 学位论文]. 呼和浩特: 内蒙 古农业大学, 2017.]

[27] Xu JZ, Xiao W, Xiao QT et al. Temporal dynamics of stable isotopic composition in Lake Taihu and controlling factors. Environment Science, 2016, 37(7): 2470-2477. [徐敬争, 肖薇, 肖启涛等. 湖水氢氧同位素组分的时间变化特征及 影响因子分析. 环境科学, 2016, 37(7): 2470-2477.]

[28] Pu JB, Li JH, Wu X et al. Hydrogen and oxygen isotope characteristics controlled by thermal stratification effect in a subtropical reservoir, SW China. Advance Water Science, 2016, 27(4) : 561-567. [浦俊兵, 李建鸿, 吴夏等. 热分层效应 控制的水库水体氢氧同位素特征. 水科学进展, 2016, 27(4): 561-567.]

[29] Pang SG, Zhao SK, Wen R et al. Spatial and temporal variation of stable isotopes in precipitation in the Haihe River basin. Chinese Science Bulletin, 2015, 60(13) : 1218-1226. DOI: 10.1360/N972014-01040. [ 庞朔光, 赵诗坤, 文蓉等. 海河 流域大气降水中稳定同位素的时空变化. 科学通报, 2015, 60(13) : 1218-1226.]

[30] Stenni B, Scarchilli C, Masson-Delmotte V et al. Three-year monitoring of stable isotopes of precipitation at Concordia Station, East Antarctica. The Cryosphere, 2016, 10(5) : 2415-2428. DOI: 10.5194/tc-10-2415-2016.

[31] Yuan RQ, Song XF, Wang P et al. Impacts of percolation in Baiyangdian Lake on groundwater. Advance Water Science, 2012, 23(6) : 751-756. [袁瑞强, 宋献芳, 王鹏等. 白洋淀渗漏对周边地下水的影响. 水科学进展, 2012, 23(6): 751-756.]

[32] West AG, February EC, Bowen GJ. Spatial analysis of hydrogen and oxygen stable isotopes ( “isoscapes”) in ground water and tap water acrossSouth Africa. Journal of Geochemical Exploration, 2014, 145(2) : 213-222.

[33] Allen ST, Keim RF, Barnard HR et al. The role of stable isotopes in understanding rainfall interception processes: a review. WIREs Water, 2017, 4: e1187. DOI: 10.1002/wat2.1187.

[34] Li WB, Li CY, Jia DB et al. Stable isotope changes of summer precipitation in Middle Inner Mongolia. Arid Zone Research, 2017, 34 (6) : 1214-1221. [李文宝, 李畅游, 贾德彬等. 内蒙古中部地区夏季大气降水同位素变化特征. 干 早区研究, 2017, 34(6): 1214- 1221.]

[35] Liu JR, Song XF, Yuan GF et al. Stable isotopic compositions of precipitation in China. Tellus Series B-Chemical \& Physical Meteorology, 2014, 66: 39-44.

[36] Dansggaard W. Stable isotopes in precipitation. Tellus, 1964, 6: 436-468.

[37] Zhang XP, Liu JM, Nakawo M et al. Vapor origins revealed by Deuterium excess in precipitation in Southwest China. Journal of Glaciology and Geocryology, 2009, 31(4): 613-619. [章新平, 刘晶沝, 中尾正义等. 我国西南地区降水中过 量気指示水汽来源. 冰川冻土, 2009, 31(4): 613-619.]

[38] Xiao K, Shen LC, Wang P. Hydrogen and oxygen isotopes of lake water and geothermal spring water in arid area of south Tibet. Environmental Science, 2014, 35(8): 2952-2958. [ 肖可, 沈立成, 王鹏. 藏南干旱区湖泊及地热水体氢氧同位 素研究. 环境科学, 2014, 35(8): 2952-2958.]

[39] Hu YD, Liu ZH, Zhao M et al. Using deuterium excess, precipitation and runoff data to determine evaporation and transpiration: A case study from the Shawan Test Site, Puding, Guizhou, China. Geochimica et Cosmochimica Acta, 2018,242 (1) : 21-33.

[40] Zhen ZL, Li WB, Li CY. Climate change record in the primary productivity of Dali-nor lake since 2100 cal.a BP. Fresenius Environmental Bulletin, 2018, 27(7) : 5096-5106. 